\title{
A FILOSOFIA JURÍDICA DE ARISTÓTELES NA PARTE GERAL DO CÓDIGO CIVIL BRASILEIRO
}

THE LEGAL PHILOSOPHY OF ARISTÓTELES IN THE GENERAL PART OF THE BRAZILIAN CIVIL CODE

Henrique Silveira Bernardes ${ }^{1}$

ISSUE DOI: $10.21207 / 1983.4225 .337$

\section{RESUMO}

Aristóteles é um dos filósofos clássicos da Grécia. Desenvolveu teorias, reflexões e conclusões importantíssimas, hoje muito utilizadas pelos diversos ramos do conhecimento, inclusive as Ciências Sociais. Seu pensamento jusfilosófico está impregnado em diversas legislações contemporâneas dos Estados, mesmo que, em alguns casos, não houve esse intuito por parte dos legisladores. O Código Civil Brasileiro de 2002 não é uma exceção, e o presente trabalho tem como objetivo a identificação de elementos aristotélicos nos dispositivos que compõem a sua Parte Geral.

Palavras-chave: Aristóteles. Direito Civil. Filosofia do Direito. Parte Geral.

\section{ABSTRACT}

\footnotetext{
${ }^{1}$ Acadêmico de Direito pela Faculdade de Direito de Franca. Pesquisador nas áreas de Direito Civil, Direito Processual Civil e Direito Constitucional.
} 
Aristotle is one of the classical philosophers of Greece. He developed very important theories, reflections and conclusions, now widely used by the various branches of knowledge, including the Social Sciences. His philosophical thinking is impregnated in several contemporary legislations of the States, even though in some cases this was not the intention of the legislators. The Brazilian Civil Code of 2002 is not an exception, and the present work has as objective the identification of Aristotelian elements in the devices that make up its General Part.

Keywords: Aristotle. Civil right. Philosophy of law. General part

\section{INTRODUÇÃO}

Aristóteles representa o apogeu do pensamento filosófico grego, e o mesmo se pode dizer para a Filosofia do Direito. Após sua morte, durante toda a Antiguidade e a Idade Média, suas reflexões jusfilosóficas foram tidas como o mais alto patamar de ideias sobre o direito e o justo já contraídas. [...] A grande excepcionalidade da Filosofia do Direito de Aristóteles se revela pela sua sistematização filosófica da justiça. As partes iniciais do Livro V da Ética a Nicômaco estão voltadas a essa questão. ${ }^{2}$

Para o aclamado filósofo grego, existem duas espécies de justiça: a Justiça Universal ou lato sensu e a Justiça Particular ou stricto sensu.

A primeira é tida como a virtude humana que precede qualquer outra, devendo estar presente em todas as demais virtudes para que essas possam ser caracterizadas como tais. Suponhamos um indivíduo que, em seu estabelecimento comercial, ouve com total dedicação e paciência tudo o que seus clientes têm a dizer. Então, ao final do dia, enquanto vai para casa, esse comerciante se depara com um morador de rua, e, ao ser abordado por ele, continua andando sem total interesse em suas palavras. Logo, o referido comerciante não pode ser considerado atencioso, pois não agiu com justiça.

A segunda é considerada a virtude máxima em si só, não dependendo de outra para complementá-la. Em sua definição clássica, consiste

\footnotetext{
${ }^{2}$ MASCARO, Alysson Leandro. Filosofia do Direito. 4. ed. - São Paulo: Atlas, 2014. p. 120.
} 
em dar a cada um o que lhe é devido. Ela pode, ainda, ser divida em distributiva e corretiva, sendo essa a que mais possui relações com o Direito Privado, o Negócio Jurídico e a Responsabilidade Civil.

\section{JUSTIÇA PARTICULAR CORRETIVA}

Nessa vertente a justiça é tratada como uma reparação do quinhão que foi, voluntária ou involuntariamente, subtraído de alguém por outrem. Assim sendo, a justiça corretiva é uma proporção aritmética, porque se trata apenas da devolução daquilo que foi acrescido a alguém. ${ }^{3}$

Percebe-se que essa é a essência do Estado de Perigo e da Lesão, localizados no Capítulo IV, intitulado Dos Defeitos do Negócio Jurídico, do Código Civil pátrio vigente.

\subsection{ESTADO DE PERIGO}

De acordo com o artigo 156 da lei civil material, configura-se o estado de perigo quando alguém, premido da necessidade de salvar-se, ou a pessoa de sua família, de grave dano conhecido pela outra parte, assume obrigação excessivamente onerosa. A solução encontrada para tal caso, em regra, é a anulação do negócio celebrado, nos termos do artigo 171 do mesmo diploma.

Para afastar a anulação do negócio e a correspondente extinção, poderá o juiz utilizar-se da revisão do negócio. ${ }^{4}$ Aí está a essência jusfilosófica aristotélica corretiva: tal revisão consistirá na redução do valor excessivamente oneroso. Assim, o réu terá que devolver a parte extra que lhe foi acrescida através de uma declaração do autor que, embora voluntária, estava contaminada.

\footnotetext{
${ }^{3}$ MASCARO, Alysson Leandro. Filosofia do Direito. 4. ed. - São Paulo: Atlas, 2014. p. 120.

4 TARTUCE, Flávio. Direito civil, 1: Lei de introdução e parte geral. 11. ed. rev., atual. e ampl. - Rio de Janeiro: Forense; São Paulo: MÉTODO, 2015. p. 21.
} 


\subsection{LESÃO}

Nos termos do artigo 157 do Código Civil, ocorre a lesão quando uma pessoa, sob premente necessidade, ou por inexperiência, obriga-se a prestação manifestamente desproporcional ao valor da prestação oposta.

De acordo com o $§ 2{ }^{\circ}$ do artigo em questão, não se decretará a anulação do negócio, se for oferecido suplemento suficiente, ou se a parte favorecida concordar com a redução do proveito. Em ambas as hipóteses, de suplementação em favor do autor ou redução do proveito por parte do réu, estão presentes reflexões de Aristóteles pelo mesmo motivo do Estado de Perigo: a correção em proporção aritmética.

\section{CRITÉRIO POLÍTICO E SOCIAL DA JUSTIÇA}

Para Aristóteles, a justiça pressupõe uma relativa igualdade, política ou social, entre os sujeitos em questão. Não há que se falar em justiça quando se trata de desiguais. Tal conclusão é retirada da própria obra do filósofo, Ética a Nicômaco.

Não devemos esquecer, porém, que o assunto de nossa investigação é ao mesmo tempo o justo no sentido irrestrito e o justo em sentido político. Este último se apresenta entre as pessoas que vivem juntas com o objetivo de assegurar a autossuficiência do grupo - pessoas livres e proporcionalmente ou aritmeticamente iguais. Logo, entre pessoas que não se enquadram nesta condição não há justiça política $[\ldots] .^{5}$

É possível notar reflexão semelhante no instituto da Representação presente na Parte Geral do Código Civil Brasileiro.

\subsection{REPRESENTAÇÃO}

${ }^{5}$ ARISTÓTELES, Ética a Nicômacos. Brasília, Ed. UnB, 1999. p. 180. 
A representação pode ser conceituada como o poder de agir em nome de outrem. De acordo com o artigo 115 do Código Civil, os poderes de representação conferem-se por lei ou pelo interessado. O primeiro modo é denominado Representação Legal, e tem, na maioria das vezes, uma íntima ligação com as pessoas naturais absolutamente incapazes. É o ensinamento do professor Flávio Tartuce:

O rol taxativo dos absolutamente incapazes, constante no art. 3. ${ }^{\circ}$ do CC/2002, envolve situações em que há proibição total para o exercício de direitos por parte da pessoa natural, o que pode acarretar, ocorrendo violação à regra, a nulidade absoluta do negócio jurídico eventualmente celebrado, conforme o art. 166, I, do mesmo diploma.

Os absolutamente incapazes possuem direitos, porém não podem exercê-los pessoalmente, devendo ser representados. ${ }^{6}$

O motivo que levou tais dispositivos a consagrarem as normas citadas anteriormente é justamente a posição de desigualdade em que se encontram os absolutamente incapazes, por terem o discernimento reduzido. Então, os atos da vida civil de tais pessoas devem ser praticados por seus respectivos representantes, que a lei determinar, estando esses em uma posição aritmética de igualdade, em questão de ponderação, com o restante da sociedade.

\section{JUSTIÇA PROPORCIONAL}

Em complemento aos tipos de justiça mencionados até então, Aristóteles faz menção à justiça proporcional, sendo essa a que deve evitar extremos. Assim sendo, o justo fica num meio-termo entre a falta e o excesso, entre o tudo e o nada. Porém, esse meio termo não é fixo, mas variável, levando em conta os elementos históricos, econômicos, sociais, culturais, políticos e costumeiros da pólis. O exemplo do professor Alysson Leandro Mascaro ilustra muito bem uma situação prática:

\footnotetext{
6 TARTUCE, Flávio. Direito civil, 1: Lei de introdução e parte geral. 11. ed. rev., atual. e ampl. - Rio de Janeiro: Forense; São Paulo: MÉTODO, 2015. p. 22.
} 
Se alguém, às margens do Rio Amazonas, delibera por fazer em seu quintal um chafariz, não faz um ato injusto, porque a água que usa em abundância não representa a carência a alguém. $\mathrm{O}$ arco do meio-termo da distribuição da água na Amazônia é largo. Mas, no deserto do Saara, se um homem delibera por fazer um chafariz, a água que utiliza para tal fim é um excesso, na medida em que há carência de tal produto aos demais. O arco do meio-termo da distribuição da água no Saara é estreito. ${ }^{7}$

Um dos princípios de interpretação dos negócios jurídicos e o princípio da socialidade trazem a justiça proporcional aristotélica intrinsecamente.

\subsection{INTERPRETAÇÃO DOS NEGÓCIOS JURÍDICOS}

De acordo com o artigo 113 do Código Civil, os negócios jurídicos devem ser interpretados conforme a boa-fé e os usos do lugar de sua celebração. Isso significa que, o que pode ser tido como justo em um local, pode ser tido como injusto em outro, levando em conta os seus usos sociais.

Como exemplo, o alqueire não possui uma medida exata em todas as regiões do Brasil. Se um indivíduo adquirir um alqueire goiano e se tornar proprietário de uma extensão de terra que possui 48.400 metros quadrados, o negócio é tido como justo. Em outra situação, se o mesmo indivíduo comprar um alqueire paulista e adquirir direitos reais sobre uma extensão de terra que possui 24.200 metros quadrados, o ato também é tido como justo. Porém, se um alqueire goiano for medido em 24.200 metros quadrados ou um alqueire paulista for medido em 48.400 metros quadrados, o negócio jurídico é tido como injusto. Percebe-se que a justiça está balizada por critérios econômicos e sociais de diversas regiões do Brasil.

\subsection{PRINCÍPIO DA SOCIALIDADE}

\footnotetext{
${ }^{7}$ MASCARO, Alysson Leandro. Filosofia do Direito. 4. ed. - São Paulo: Atlas, 2014. p. 23.
} 
Por esse princípio, o Código Civil de 2002 procura superar o caráter individualista e egoísta que imperava na codificação anterior, valorizando a palavra nós, em detrimento da palavra eu. Os grandes ícones do Direito Privado recebem uma denotação social: a família, o contrato, a propriedade, a posse, a responsabilidade civil, a empresa, o testamento. ${ }^{8}$

A Justiça Proporcional está presente em tal princípio pelo fato de o critério social ser uma das medidas do justo. Além disso, a conciliação entre o indivíduo e a sociedade é algo que sempre preocupou Aristóteles, de acordo com Judith Martins-Costa:

Dúvidas não há de que o Direito Civil em nossos dias é também marcado pela socialidade, pela situação de suas regras no plano da vida comunitária. A relação entre a dimensão individual e a comunitária do ser humano constitui tema de debate que tem atravessado os séculos desde, pelo menos, Aristóteles, constituindo, mais propriamente, um problema de filosofia política, por isso devendo ser apanhado pelo Direito posto conforme os valores da nossa experiência jurídica. ${ }^{9}$

Aristóteles também sempre defendeu que não há uma ambigüidade entre os interesses individuais e sociais. De acordo com ele, tais interesses devem ser complementares, balanceados, pois a sociedade não existe para garantir benefícios a cada indivíduo isoladamente, mas possui uma finalidade muito maior: o benefício social. Tal afirmação é retirada de uma das principais obras do filósofo: A Política.

Assim, o homem é um animal cívico, mais social do que as abelhas e os outros animais que vivem juntos. [...] O Estado, ou a sociedade política, é até mesmo o primeiro objetivo a que se propôs a natureza. O todo existe necessariamente antes da parte. As sociedades domésticas e os indivíduos não são senão as partes

\footnotetext{
${ }^{8}$ TARTUCE, Flávio. Direito civil, 1: Lei de introdução e parte geral. 11. ed. rev., atual. e ampl. - Rio de Janeiro: Forense; São Paulo: MÉTODO, 2015. p. 29.

${ }^{9}$ MARTINS-COSTA. Judith. O Novo Código Civil Brasileiro: Em Busca da 'Ética da Situação". In Diretrizes Teóricas do Novo Código Civil Brasileiro. São Paulo: Editora Saraiva, 2002. p. 56.
} 
integrantes da Cidade, todos subordinados ao corpo inteiro, todas distintas por seus poderes e suas funções, e todas inúteis quando desarticuladas, semelhantes às mãos e aos pés que, uma vez separados do corpo, só conservam o nome e a aparência, sem a realidade, como uma mão de pedra. O mesmo ocorre com os membros da Cidade: nenhum pode bastar-se a si mesmo. Aquele que não precisa dos outros homens, ou que não pode resolver-se a ficar com eles, ou é um deus, ou um bruto. Assim, a inclinação natural leva os homens a este gênero da sociedade. ${ }^{10}$

Durante a Idade Moderna e até mesmo no início da Idade Contemporânea, muitas vezes os interesses individuais eram separados dos coletivos. O Princípio da Socialidade não instaurou com exclusividade no Direito Privado a conciliação entre o indivíduo e seu meio, mas a reforçou e a deixou mais explícita.

É importante destacar que tal princípio está presente não apenas na Parte Geral do Código Civil de Miguel Reale, mas também em sua Parte Especial.

\section{VOLUNTARIEDADE DOS SUJEITOS}

Para Aristóteles, a justiça não é algo abstrato, mas concreto. Não é um saber, mas uma ação. E não basta que essa concretude se dê objetivamente: deve haver a intenção do agente em sua prática. $\mathrm{O}$ mesmo se pode dizer em relação à injustiça.

A excelência moral se relaciona com as emoções e ações, e somente as emoções e ações voluntárias são louvadas e censuradas, enquanto as involuntárias são perdoadas, e às vezes inspiram piedade; logo, a distinção entre o voluntário e o involuntário parece necessária aos estudiosos da natureza da excelência

${ }^{10}$ ARISTÓTELES. A política. São Paulo, Martins Fontes, 2000. p. 181. 
moral, e será útil também aos legisladores com vistas à atribuição de honrarias e à aplicação de punições. ${ }^{11}$

É válido dizer que tal pensamento filosófico influenciou o ordenamento jurídico de grande parte dos Estados, principalmente em se tratando do Direito Penal. Porém, o presente trabalho está restrito à Parte Geral do Código Civil Brasileiro de 2002.

\subsection{DOS ATOS ILÍCITOS}

De acordo com o artigo 186 do diploma civil, aquele que por ação ou omissão voluntária, negligência ou imprudência, violar direito e causar dano a outrem, ainda que exclusivamente moral, comete ato ilícito. $\mathrm{O}$ dispositivo consagra a voluntariedade como elemento determinante de ilicitude e, por extensão, considera que se não há espontaneidade na ação, não há injustiça por parte do sujeito.

A voluntariedade é tão importante que, em alguns casos, dependendo da intenção do agente, um ato considerado ilícito pode se tornar lícito. Por exemplo, se alguém está dirigindo um veículo e, por culpa em sentindo amplo (dolo e culpa em sentindo estrito, a qual envolve imprudência, negligência e imperícia) avança contra o portão de um imóvel e o deteriora, considera-se que o sujeito cometeu um ato ilícito. Mas, se em outra circunstância, o agente deteriora o portão de um imóvel para evitar o atropelamento de uma criança, que inesperadamente se colocou em frente ao veículo em movimento, o ato é tido como lícito, porque a intenção da ação foi salvar a vida de um ser humano. Consequentemente é considerado justo.

\subsection{DO NEGÓCIO JURÍDICO}

Esse instituto pode ser conceituado como sendo toda a ação humana, de autonomia privada, com a qual os particulares regulam por si os

${ }^{11}$ ARISTÓTELES. Ética a Nicômacos. Brasília, Ed. UnB, 1999. p. 132. 
próprios interesses, havendo uma composição de vontades, cujo conteúdo deve ser lícito. ${ }^{12}$

No entanto, em alguns casos, a exteriorização da vontade de um dos agentes pode estar viciada, por elementos como o erro ou ignorância, o dolo, a coação, o estado de perigo e a lesão. São os chamados Defeitos do Negócio Jurídico.

O artigo 171 do Código Civil prevê a anulabilidade do negócio jurídico cuja exteriorização da vontade estava contaminada, pois não havendo o elemento vontade em sua integridade, o ato não é tido como justo.

A coação e a ignorância ou erro possuem uma peculiaridade ainda maior para Aristóteles, porque não configuram a mínima vontade de agir com justiça ou injustiça, mesmo quando objetivamente resultam em algo bom ou ruim. Isso se dá porque as forças externas ao agente ou sua falta de conhecimento anulam totalmente qualquer intenção. Tal ensinamento é retirado do professor Alberto Alonso Muñoz, ao interpretar textos do filósofo que constitui o tema central desse trabalho:

Uma ação é voluntária, de toda forma, ao menos se o princípio da ação está no agente e se ele não age ignorando. Mas a condição básica para que o agente possa agir diferentemente e ser, portanto, responsável por sua ação, é que já possua plenamente desenvolvida a faculdade de deliberar. [...] Uma ação voluntária, agora introduzindo as demais condições, é aquela que resulta, a partir de um estímulo, da natureza própria do agente naquele momento que pode vir a ser mudada, sem que esta fosse contradita por uma causalidade que anula estas condições ou por uma falha no sistema de informações do agente. ${ }^{13}$

Para Aristóteles, a vontade é o que caracteriza a justiça ou a injustiça. Para o Direito Civil, a vontade é a base do Negócio Jurídico.

\footnotetext{
${ }^{12}$ TARTUCE, Flávio. Direito civil, 1: Lei de introdução e parte geral. 11. ed. rev., atual. e ampl. - Rio de Janeiro: Forense; São Paulo: MÉTODO, 2015. p. 29.

${ }^{13}$ MUÑOZ, Alberto Alonso. Liberdade e causalidade: ação, responsabilidade e metafísica em Aristóteles. São Paulo, Discurso Editorial, 2002. p. 74.
} 


\section{$5 \quad$ A INTENÇÃO DE SER INJUSTIÇADO}

Muito se tem questionado filosoficamente sobre o sujeito passivo dos atos tidos como justos ou injustos, mais especificamente a respeito da sua intenção em ser ou não alvo de injustiça. Para Aristóteles, o elemento vontade também constitui a essência da resposta para essa pergunta. De acordo com ele, se a ação injusta está em consonância com a vontade do agente passivo, pode-se dizer que a mesma produziu resultados injustos, mas o ato considerado em si não o é.

O artigo 110 do Código Civil, in fine, adotou regra semelhante em seu caput. De acordo com ele, a manifestação de vontade subsiste ainda que o seu autor haja feito a reserva mental de não querer o que manifestou, salvo se dela o destinatário tinha conhecimento. A título de exemplo, suponha um escritor que promete doar todo o lucro de determinada obra para uma instituição de caridade, mas na verdade está usando tal artifício apenas para ter sucesso nas vendas e a referida instituição tem consciência disso. No final das contas, essa não poderá exigir que o lucro da obra lhe seja entregue, porque estava ciente da injustiça que estava sendo praticada contra si e, portanto, o ato é tido como justo.

O filósofo também questiona se é possível um sujeito cometer um ato injusto contra si, e o mesmo responde que não: a injustiça apenas se dá com o próximo. É o brocardo latino ubi societas, ibi jus (onde está a sociedade, ali está o direito).

\section{$6 \quad$ EQUIDADE}

É praticamente impossível falar sobre filosofia jurídica aristotélica sem falar de Equidade. Para o referido filósofo, a equidade é o elemento superior da justiça, pois consiste na consideração das especialidades de cada caso concreto, resultando na adequação do geral ao peculiar. Aristóteles não considerava uma tarefa árdua, pois na Grécia Antiga não havia a exaltação do positivismo jurídico como na era contemporânea. Lá, as leis eram elaboradas diretamente pelos cidadãos, e, devido a isso, tinham em sua essência uma grande manifestação social. Então, a lei era vista como muito justa, e a equidade que adaptasse a lei também era vista como justa. Não eram, portanto, antagônicas, mas complementares, uma fundamentando a existência da outra. 
Aristóteles também retira da Equidade o fundamento para conceituar o Direito Natural. Enquanto os filósofos mais importantes da idade média, moderna e até mesmo contemporânea definem o jusnaturalismo como o Direito anterior e superior ao homem, Aristóteles defende que o mesmo consiste em uma análise específica da essência e natureza das pessoas, das circunstâncias e dos casos levados a julgamento. Tal afirmação é extraída dos ensinamentos de Aloysio Ferraz Pereira:

Esse direito é natural porque deriva da natureza complexa de Aristóteles, que se não reduz ao determinismo, à quantidade e à causalidade mecânica, próprios do sentido que adquiriu a partir de Descartes. Nessa natureza o direito, que deriva dela, tem um conteúdo material, uma forma inteligível e um fim a que se refere, além de uma causa eficiente. É um direito vivo, que, por isso mesmo, não sobreviveu à por assim dizer natureza morta da era cartesiana, em que ainda vivemos. E aquele fim se nos oferece na natureza mesma; de resto, desde sempre se nos mostrou através simplesmente da observação. Esta aliás não se faz como um registro passivo. [...]

A teoria do direito natural pode ser definida como um método experimental. Antecipa-se ao direito comparado e à sociologia. Sujeito às coordenadas de tempo e espaço, adapta-se às circunstâncias de cada grupo social politicamente organizado. Mas, com a ajuda do direito natural, nunca se descobrirá nem se há de jamais elaborar um código de leis imutáveis e definitivas. ${ }^{14}$

O Código Civil de 2002 trouxe uma grande valorização da equidade em alguns de seus dispositivos, inclusive da Parte Geral.

\subsection{AUSÊNCIA}

${ }^{14}$ PEREIRA, Aloysio Ferraz. História da filosofia do direito: das origens a Aristóteles. São Paulo: Revista dos Tribunais, 1980. p. 141. 
Desaparecendo uma pessoa do seu domicílio sem dela haver notícia, se não houver deixado representante ou procurador a quem caiba administrar-lhe os bens, o juiz, a requerimento de qualquer interessado ou do Ministério Público, declarará a ausência e nomear-lhe-á curador (Art. 22). Decorrido um ano da arrecadação dos bens do ausente, ou, se ele deixou representante ou procurador, em se passando três anos, poderão os interessados querer que se declare a ausência e se abra provisoriamente a sucessão (Art. 26).

É no artigo 29 que se encontra a equidade. Assim que a sucessão provisória for aberta, antes da partilha dos bens, o juiz, quando julgar conveniente, ordenará a conversão dos bens móveis, sujeitos a deterioração ou a extravio, em imóveis ou em títulos garantidos pela União. Tal preceito demonstra a clara adaptação da lei ao caso específico, pois nem sempre existirão bens móveis que se enquadrarão nas hipóteses do caput.

\subsection{COAÇÃO}

A coação, para viciar a declaração da vontade, há de ser tal que incuta ao paciente fundado temor de dano iminente e considerável à sua pessoa, à sua família, ou aos seus bens. Porém, o parágrafo único do artigo 151 determina que se disser respeito a pessoa não pertencente à família do paciente, o juiz, com base nas circunstâncias, decidirá se houve coação. A ratio legis de tal determinação é que, às vezes, alguns entes próximos não pertencentes aos laços familiares possuem uma significante importância para o agente coagido.

$\mathrm{O}$ artigo 152 determina que no apreciar a coação, ter-se-ão em conta o sexo, a idade, a condição, a saúde, o temperamento do paciente e todas as demais circunstâncias que possam influir na gravidade dela. Podese dizer, com toda a certeza, que tal dispositivo é o mais equitativo da Parte Geral do Código Civil, pois leva em consideração várias características subjetivas do agente que podem tornar um caso extremamente específico, merecendo também uma análise específica.

\subsection{ESTADO DE PERIGO}


Já mencionado anteriormente no presente artigo, o estado de perigo possui mais um preceito relacionado à equidade. De acordo com o seu parágrafo único, tratando-se de pessoa não pertencente à família do declarante, o juiz decidirá segundo as circunstâncias. A ratio legis é a mesma do parágrafo único do artigo 151, já mencionado no tópico anterior.

\section{A EQUIDADE E FLEXIBILIDADE DO CÓDIGO CIVIL}

Para evitar a sua rápida desatualização diante de uma sociedade tão dinâmica quanto a atual, o Código Civil de 2002 passou do sistema fechado ao semi-aberto, adotando alguns dispositivos que dão uma maior flexibilidade ao juiz. Tais dispositivos são denominados cláusulas gerais e conceitos legais indeterminados.

\subsection{CLÁUSULAS GERAIS}

As cláusulas gerais são normas elásticas, apresentam conceitos cujos vocábulos empregados pelo legislador têm densidade semântica intencionalmente vaga e aberta, permitindo ao juiz preenchê-las com valores a serem empregados no julgamento de cada caso singular. Não oferece a solução a ser dada, de sorte não prevê a consequência jurídica, consentindo ao juiz criar soluções, vale dizer, abre-lhe à função criadora. ${ }^{15}$

Ao adotar tal técnica legislativa, o Código Civil foi bem leal a Aristóteles, que sempre valorizou a análise específica de cada caso levado a julgamento para que a norma pudesse ser adaptada antes de ser aplicada. Ensinam Nelson Nery e Rosa Nery:

[...] Quando a norma não prevê a consequência, dando ao juiz a oportunidade de criar a solução, dá-se ocasião de aplicação da cláusula geral: a consequência não estava prevista na norma e foi criada pelo juiz para o caso concreto. $\mathrm{O}$ juiz pode dar uma solução em um determinado caso, e outra

\footnotetext{
${ }^{15}$ BIANCO, João Carlos. Os Princípios Fundantes no Direito das Obrigações. Revista
} Eletrônica da Faculdade de Direito de Franca. v. 8, n.1, jul/2013, ISSN: 1983-4225. 
solução diferente em outro caso, aplicando a mesma cláusula geral. ${ }^{16}$

Contudo, a liberdade do juiz não é plena, uma vez que ele não pode se valer de seus valores pessoais e muito menos ser arbitrário ao preencher essas normas. Tal afirmação é baseada no princípio processual da imparcialidade.

\subsection{CONCEITOS LEGAIS INDETERMINADOS}

Os conceitos legais indeterminados, com significado paralelo às cláusulas gerais, são também normas elásticas, nas quais são introduzidos conceitos propositadamente vagos e abertos, proporcionando ao juiz preenchê-los com valores a serem empregados no julgamento de cada caso singular, com a diferença de preverem a consequência jurídica, isto é, como que aquele caso deva ser solucionado. Atiça a função criadora do juiz, conquanto com menor ênfase, pois cabe a ele a escolha de valores sociais que irão presidir o caso em julgamento. ${ }^{17}$

Tal técnica legislativa reduz o exercício da equidade por parte do juiz, uma vez que ele não pode criar a solução para o caso concreto, estando este previsto na norma. Contudo, não se pode dizer que ela é totalmente escassa, uma vez que os preceitos vagos ainda merecem uma atenção especial em relação às circunstâncias peculiares do caso levado a julgamento.

\section{CONSIDERAÇÕES FINAIS}

O pensamento de Aristóteles sobre o Direito não se limita ao aqui exposto - eis que no presente trabalho foram mencionados apenas aqueles que estão impregnados na Parte Geral do Código Civil de 2002. É importante ressaltar que a justiça aristotélica também está presente no Direito das

\footnotetext{
${ }^{16}$ NERY JUNIOR, Nelson et al. Código civil anotado e legislação extravagante, 2 ed. São Paulo: RT, 2003. p. 66.

${ }^{17}$ BIANCO, João Carlos. Os Princípios Fundantes no Direito das Obrigações. Revista Eletrônica da Faculdade de Direito de Franca. v. 8, n.1, jul/2013, ISSN: 1983-4225.
} 
Obrigações, Direito de Empresa, Direito das Coisas, Direito de Família e Direito das Sucessões.

O filósofo também muito contribuiu para outros ramos do Direito - inclusive do Direito Público, já que muito refletiu sobre temas como Política, Estado e vida em sociedade. Além disso, possui um grande papel nos Direitos Humanos, levando em consideração que debateu temas sobre a escravidão e o tratamento igualitário de todos perante a lei.

Aristóteles foi considerado um dos maiores jusfilósofos de seu tempo, e assim continuou durante um longo período, já que muitos posteriores lhe foram fiéis. Além disso, ele possui, até hoje, uma grande influência em todo o ordenamento jurídico de vários países do mundo.

\section{REFERÊNCIAS BIBLIOGRÁFICAS}

MASCARO, Alysson Leandro. Filosofia do Direito. 4. ed. - São Paulo: Atlas, 2014.

TARTUCE, Flávio. Direito civil, 1: Lei de introdução e parte geral. 11. ed. rev., atual. e ampl. - Rio de Janeiro: Forense; São Paulo: MÉTODO, 2015.

ARISTÓTELES, Ética a Nicômacos. Brasília, Ed. UnB, 1999.

MARTINS-COSTA. Judith. O Novo Código Civil Brasileiro: Em Busca da 'Ética da Situação". In Diretrizes Teóricas do Novo Código Civil Brasileiro. São Paulo: Editora Saraiva, 2002.

MUÑOZ, Alberto Alonso. Liberdade e causalidade: ação, responsabilidade e metafísica em Aristóteles. São Paulo, Discurso Editorial, 2002.

PEREIRA, Aloysio Ferraz. História da filosofia do direito: das origens a Aristóteles. São Paulo: Revista dos Tribunais, 1980. BIANCO, João Carlos. Os Princípios Fundantes no Direito das Obrigações. Revista Eletrônica da Faculdade de Direito de Franca. v. 8, n.1, jul/2013, ISSN: 1983-4225.

NERY JUNIOR, Nelson et al. Código civil anotado e legislação extravagante, 2 ed. São Paulo: RT, 2003. 